\title{
Erratum to: A modern version of Lewis's theory of valency
}

\section{Peter G. Nelson ${ }^{1}$}

\section{Erratum to: Found Chem (2015) 17:153-162 \\ DOI 10.1007/s10698-015-9217-0}

The original version of this article was published with certain errors that are corrected below:

The spaces in some of the formulae are not as clear as they should be. This applies particularly to the formula for $\left[\mathrm{HF}_{2}\right]^{-}$, which should read:

$$
[\because \ddot{\mathrm{F}}: \mathrm{H}: \ddot{\mathrm{F}}:]^{-}
$$

Also, the formula for $(\mathrm{Me})_{3} \mathrm{NO}$ has a space in it, which should not be there. This should read:

$$
(\mathrm{Me}:)_{3} \mathrm{~N}: \ddot{\mathrm{O}}:
$$

The online version of the original article can be found under doi:10.1007/s10698-015-9217-0.

\section{$\bowtie$ Peter G. Nelson}

p.g.nelson@hull.ac.uk

1 Department of Chemistry, University of Hull, Hull HU6 7RX, UK 